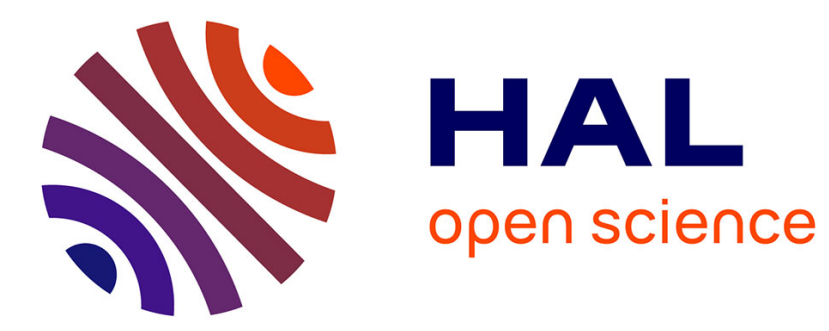

\title{
Understanding Early Technology Adoption by the Emergent Older Adults in Dharavi
}

\author{
Shaon Sengupta, Sayan Sarcar, Anirudha Joshi
}

\section{To cite this version:}

Shaon Sengupta, Sayan Sarcar, Anirudha Joshi. Understanding Early Technology Adoption by the Emergent Older Adults in Dharavi. 16th IFIP Conference on Human-Computer Interaction (INTERACT), Sep 2017, Bombay, India. pp.504-508, 10.1007/978-3-319-68059-0_61 . hal-01679800

\section{HAL Id: hal-01679800 https://hal.inria.fr/hal-01679800}

Submitted on 10 Jan 2018

HAL is a multi-disciplinary open access archive for the deposit and dissemination of scientific research documents, whether they are published or not. The documents may come from teaching and research institutions in France or abroad, or from public or private research centers.
L'archive ouverte pluridisciplinaire HAL, est destinée au dépôt et à la diffusion de documents scientifiques de niveau recherche, publiés ou non, émanant des établissements d'enseignement et de recherche français ou étrangers, des laboratoires publics ou privés. 


\title{
Understanding Early Technology Adoption by the Emergent Older Adults in Dharavi
}

\author{
Shaon Sengupta, Sayan Sarcar, Anirudha Joshi \\ Indian Institute of Technology, Bombay, Kochi University of Technology, Japan \\ shaon.sengupta@gmail.com \\ mailtosayan@gmail.com.
}

\begin{abstract}
This field trip proposes a two-day program to understand and evaluate technology adoption of digital wallets among the elderly population in one of the urban slums of Mumbai, through training, probes and shadowing. The aim of the study is to analyse perceived challenges, influences \& motivations, barriers to adoption and issues faced during wallet transactions. The findings from this study will be interpreted to formulate design recommendations and guidelines, useful to deploy meaningful propositions suitable for the elderly population, especially to facilitate a smooth transition to the digital vision of India.
\end{abstract}

Keywords: Emergent users, elderly, digital wallets, demonetization, India

\section{Introduction}

On the evening of Nov. 08, the Prime Minister of India announced demonetization of the Rs.500 and Rs.1,000 notes, the two big currency denominations that account for $86 \%$ of the money in circulation [1]. The move was an effort to stop counterfeiting of the current banknotes allegedly used for funding terrorism, as well as a devise to crackdown on black money in the country [2]. In the long-term, India aimed to become a cashless society and embrace the transparency of currency digitization.

However, in the days following the announcement, the country witnessed severe cash shortages that caused great inconveniences to its people. A large mass of the Indian population, who are disadvantaged by the 'digital divide' - the gap that stops people from benefiting from ICTs [3], could not quite comprehend the cashless vision and lined-up to withdraw their money, standing in serpentine queues. The poor, the disabled and elderly citizens were most inconvenienced, as they had to wait for long hours to withdraw money. This led to several unfortunate deaths due to anxiety, panic and exhaustion.

This disadvantaged population that India hosts, are the emergent users - those who are less educated, economically disadvantaged, geographically dispersed, and culturally heterogeneous [3]. The user-usage model for the emergent user reports that age and educational levels are the highest significant predictors of technology usage for the emergent users. It also states that the emergent users are likely to be Basic Users 
and Navigators. We can extrapolate this model to state that young people are more likely to be more tech-savvy. Conversely, older people are expectedly less tech-savvy. The study also states that for such users, the task typologies of 'Text Inputter', 'Transactor' and 'Account Holder' should be avoided [3].

Clearly, in the context of how the elderly population is coping at this time of currency distress is understandable. The download rates of such mobile wallets and other digital mechanisms have been rather sparse. This digital barrier and eventual conversion to be able to be a 'Transactor' requires a combination of several facets. It includes understanding of the concept of a virtual personal wallet, a digital identity of an account holder, and trust in the virtual banking system to carry out the transactions, which are barriers for the senior population who perhaps do not have the requisite mental model for the same [3]. The confluence of this necessary conversion (Being a 'Transactor' of a mobile wallet) vis-a-vis the seemingly constant stage of use ('Unexposed', and no prior intention to progress) of the elderly, brings us to an opportunity for an interesting research space, which defines the motivation of this study. Hence, this study will particularly focus on issues and concerns that arise in the early phase of technology adoption by this particular population group.

\section{Background}

With the expansion of digital age, it is imperative that as a society, we need to brace for a future that takes care of its elderly. There are known challenges that they face, including impairment of special sensory functions like vision and hearing, decline in overall immunity, age related physiologic changes (motor skills, frailty), morbidities due to ageing of the brain, socio-economic factors such as breakdown of the family support systems and decrease in economic independence and decreasing funds. Socioeconomic factors such as breakdown of the family support systems also lead to a host of psychological illnesses. Topped to this, is the risk and genetic predisposition to acquire chronic diseases, such as anemia, hypertension, dementia, Alzheimer's, chronic obstructive airway disease (COAD), cataract etc. the senior population are becoming vulnerable more rapidly than we would imagine.

Naturally, older adults find adoptions to new technologies difficult. There are unique barriers to this adoption like physical challenges, skeptical attitudes and difficulty in learning new things [6]. Combined to this is the physical aspect of the mobile phones where size of the screen, sound quality or voice inputs are often not compatible to the needs of the elderly [5]. Elderly also use only a limited set of functions in their mobiles phones and have a lack of understanding of hierarchical menus [5].

It will be worthwhile to investigate in the context of these known challenges to understand how such models might help to design solutions that help manoeuvre the difficulties around the imminent era of cashless society. 


\section{Plan}

\subsection{User group, recruitment and facilitation}

Owing to the unique limitations of emergent users and the specific challenges of old age that adds to this situation, the study focuses on the elderly fraction of the emergent user group. The study proposes Emergent Older Adults between age 60-75.

The study recommends the following recruitment criteria for the users:

-Are in possession of a smart phone

-Have no prior exposure to any digital payments (e.g. mobile wallets etc.)

-Are physically fit and mobile

The recruited users will be paid Rs.500 as a token compensation that will be loaded in their digital wallets. The decision of the goods purchased with this amount will be a prerogative of the users. Through this exercise, the participants will be educated/trained to use an online wallet application. The outcomes of this study will also aim to work as design inputs for designers of such wallets, as they will be conscious about the specific needs of the elderly population., which in turn will be suitable for participants and users of similar profile.

\subsection{Location: Dharavi}

The study is proposed to be conducted at Dharavi, owing to its potential in translating its business acumen and eventually surviving the cashless journey. Dharavi was founded in 1882 during the British colonial era. The slum grew in part because of an expulsion of factories and residents from the peninsular city-centre by the colonial government, and from rural poor migrating into urban Mumbai. It is currently a multireligious, multi-ethnic, diverse settlement. Estimates of Dharavi's total population vary between 700,000 to about 1 million. With recent digitalization programs in several pockets of Dharavi, it becomes important to see how this acceleration aids in empowering its elderly. How digitalization of the immediate context might have the potential to promote knowledge, openness and adoption of its elderly. To recruit appropriate users in this location, we will need to work with local organisations.

\subsection{Method: Technology Probe}

A technology probe will be used in this study to understand and map user behaviour. A suitable example is Paytm, the most popular mobile wallet in India, today. The method will consist of the following steps:

Day 1

- 9 am-11 am Introduction to wallets, training, loading, mutual exchange 
- $\quad 11 \mathrm{am}-1 \mathrm{pm} \quad$ First shopping experience along with the participant

- $\quad 2$ pm- 4 pm Shadowing the users to understand tasks \& behaviour

Day 2

- $\quad 10 \mathrm{am}-12 \mathrm{pm} \quad$ Focus group and discussion with the users

- 1 pm-3 pm Wrap up, summarising and recommendations

Training will include helping users understand the concept of digital wallets, downloading the relevant wallet app in their phones, explaining basic features and key use cases and setting expectation of the study. The study will also seek approval from the users owing to their age, possible health threats and their consent to use their experiences to draw inferences. Notes on planning - Field trip is suggested for 2 days where we will be testing PayTM mobile app. Place for research is Dharavi as it is technologically advanced while being a slum. However, any other comparable location is acceptable.

\subsection{Participants}

Group Facilitator (1) - Shaon Sengupta - PhD Candidate at IDC, IIT Bombay, with focused interest in the elderly population. Role to help with training, time keeping and consolidation of activities.

Senior Researcher (1) - Sayan Sarcar- Post Doc researcher from KUT, Japan. The researcher brings thorough understanding and expertise of research techniques to trigger and provoke users during focus groups and the project team during the brainstorming session.

Field representatives (3) - Andreea Ioana Niculescu, Lou-Ann Castelino, Anjali Kukreja. To help lead in observation and shadowing activities. This position seeks knowledge of Hindi and Marathi and a combination of male and female candidates.

Designer (1) - Pratiksha Dixit - To help in creating quick mock-ups of ideas and simulations to connect recommendations to visualized sketches.

\section{4. $\quad$ Expected Outcomes}

The outcome of the two-day trip will include a highly engaging report and presentation consolidating top findings and insights drawn from observations, artefacts, verbatims etc. The findings will further be used to create design recommendations and guidelines for design payment mechanism that are suitable to our target population. The design recommendations will finally lead to quick prototypes demonstrating the translation of issues and relevant design visualisations. 


\section{References}

1. Quartz India, Timeline: 20 days of demonetisation, Narendra Modi's biggest gamble with the Indian economy. http://qz.com/846454/timeline-20-days-of-demonetisation-narendramodis-biggest-gamble-with-the-indian-economy/

2. Indian 500 and 1000 rupee note demonetisation https://en.wikipedia.org/wiki/Indian_500_and_1000_rupee_note_demonetisation/

3. Devanuj, Joshi. Technology Adoption by 'Emergent' Users - The User-Usage Model. APCHI (2013). Bangalore.

4. Dharavi. https://en.wikipedia.org/wiki/Dharavi

5. Renaud, Biljon. Predicting Technology Acceptance and Adoption by the Elderly: A Qualitative study. SAICSIT (2008) South Africa

6. Older Adults and Technology Use http://www.pewinternet.org/2014/04/03/older-adults-and-technology-use/

7. Jen Liu, Ching Yang. Using the Technology Acceptance Model to Examine Seniors' Attitudes toward Facebook. International Scholarly and Scientific Research \& Innovation (2014) 